\title{
Utilization of Anthranilic and Nitrobenzoic Acids by Nocardia opaca and a Flavobacterium
}

\author{
By R. B. CAIN \\ Department of Microbiology, Oklahoma State University, \\ Stillwater, Oklahoma, U.S.A. and Department of Botany, \\ University of Nerocastle upon Tyne*
}

(Received 11 May 1965, accepted 16 September 1965)

\begin{abstract}
SUMMARY
Anthranilic and o-nitrobenzoic acids act as mutual inhibitors of both growth and substrate oxidation for Nocardia opaca and a flavobacterium which can utilize either substance as sole source of carbon, nitrogen and energy. Growth of the former bacterium on anthranilate induced, apparently simultaneously, both the transport system for anthranilate uptake and the enzymic mechanism necessary for its complete oxidation to $\mathrm{CO}_{2}$ and $\mathbf{N H}_{3}$. Among the enzymes induced by anthranilate was the complete sequence that oxidizes catechol to $\beta$-oxoadipate; this was absent from organisms grown in fumarate or glucose media. The properties of the first enzyme in this sequence, a catechol-1,2-oxygenase, differ in several features from those of the same enzyme induced in this bacterium by growth on 0 -nitrobenzoic acid.
\end{abstract}

\section{INTRODUCTION}

Anthranilic (o-aminobenzoic) acid is an important intermediary metabolite in both biosynthetic and catabolic pathways in micro-organisms. It serves for instance as a precursor for tryptophan in Aerobacter aerogenes and Escherichia coli (Doy \& Gibson, 1961), in Neurospora crassa (Yanofsky, 1956; Yanofsky \& Rachmeler, 1958) and in saccharomyces mutants (Lingens, Hildinger \& Hellman, 1958). Hydroxylation of anthranilic acid, in the 3-position, has been observed with rat liver preparations (Wiss \& Hellman, 1953) but no hydroxylation of anthranilic acid has been conclusively demonstrated in micro-organisms. The finding, by sequential induction methods, that 5-hydroxyanthranilic acid may be a product of anthranilic acid metabolism by an achromobacter (Ladd, 1962) remains the only indication at present that bacteria might hydroxylate the ring of this substrate during metrbolism. Anthranilic acid has also been known for some time as an intermediate in the aerobic dissimilation of L-tryptophan by micro-organisms, especially pseudomonas species which use the 'aromatic pathway' (Suda, Hayaishi \& Oda, 1950; Knox, 1959); it occupies a similar position in degradation of the D-isomer (Behrman 1962; Martin \& Durham, 1962). Reduction of 0 -nitrobenzoic acid by a flavobacterium (Cain, 1966) and Nocardia opaca (Cain, 1958; Cartwright \& Cain, $1959 b$ ) yields anthranilic acid, but the amino compound is not an obligatory intermediate on the direct energy-yielding pathway of degradation of $o$-nitrobenzoic

* Present address. 
acid by these organisms (Ke, Gee \& Durham, 1959; Cain, 1966). Both species, nevertheless, will utilize anthranilic acid separately as sole source of carbon, nitrogen and energy as does the achromobacter isolated by Ladd (1962), but the pathways of utilization by these three organisms appear to be different.

The present paper describes some observations made on the growth patterns of Nocardia opaca and a flavobacterium which can utilize anthranilic and o-nitrobenzoic acids, and the unusual mutually antagonistic effects of these substrates when present together in the medium.

\section{METHODS}

Organisms. The two bacteria used in this study were strain 06 of Nocardia opaca (Cain, 1958) and a flavobacterium isolated by Durham \& Hubbard (1959). They were maintained on slopes of nutrient agar and on the defined medium solidified with $2 \%(w / v)$ New Zealand agar. The ELH ${ }^{-}$mutant of Pseudomonas putida, provided by Dr N. Ornston, was grown upon the defined medium containing succinate and $0 \cdot 1 \%(\mathrm{w} / \mathrm{v})$ benzoic acid to induce muconolactone isomerase (Ornston \& Stanier, 1964).

Media. The medium for bulk growth of organisms consisted of (g./I.): organic source, $1.0 ; \mathrm{K}_{2} \mathrm{HPO}_{4}, 1.0 ; \mathrm{MgSO}_{4} .7 \mathrm{H}_{2} \mathrm{O}, 0.1 ;$ trace elements solution (Barnett \&

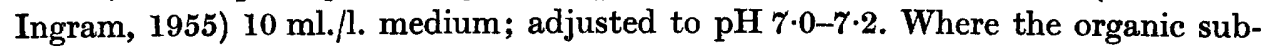
strate did not provide a source of nitrogen $\left(\mathrm{NH}_{4}\right)_{2} \mathrm{SO}_{4}(0.5 \mathrm{~g} . / 1$.) was included. Yields of organism were improved by adding $0.02 \%(\mathrm{w} / \mathrm{v})$ Difco yeast extract or 'Marmite' (a British commercial yeast-extract preparation).

Growth experiments. These were done in new stout-walled Pyrex tubes selected for the best optical matching after rigorous cleaning. The defined medium (GM) was dispensed in $5 \mathrm{ml}$. volumes and consisted of: substrate, 0-10 mM; $\mathrm{K}_{2} \mathrm{HPO}_{4}, 0 \cdot 1 \mathrm{M}$; $\mathrm{MgSO}_{4} \cdot 7 \mathrm{H}_{2} \mathrm{O}, 1 \mathrm{~mm}$; inhibitor (or alternative substrate), 0-10 mM; adjusted to $\mathrm{pH} 7 \cdot 2$ before autoclaving. The tubes were inoculated with $0.1 \mathrm{ml}$. of a suspension of either organism grown on the appropriate substrate, harvested, washed twice and resuspended in sterile distilled water to an extinction value of 0.4 at the appropriate wavelength. All cultures were incubated at $30^{\circ}$ with the tubes racked at $45^{\circ}$ from the vertical and shaken in a reciprocating shaker (96 strokes/min.; throw, $5.5 \mathrm{~cm}$.). Uniform turbid growth was ensured only by agitation; stationary cultures of Nocardia opaca developed a surface pellicle and granular growth. Growth was measured turbidimetrically at $530 \mathrm{~m} \mu$.

Growth yield coefficients. Determinations of yield coefficients were made in $250 \mathrm{ml}$. Erlenmeyer flasks fitted with a side-arm suitable for determination of turbidity in the Bausch-Lomb 'Spectronic 20' spectrophotometer.

Triplicate flasks contained $30 \mathrm{ml}$. of the defined (GM) medium containing up to $300 \mu$ moles of substrate. Because in such cases nitrogen might have been the limited factor, excess $\mathrm{NH}_{4} \mathrm{Cl}(0.1 \%$, w/v) was added in other experiments because it is known (Cain, 1958; Cartwright \& Cain, 1959a) that the nitrogen from nitro- and amino-benzoates appears in the medium largely as ammonia. The flasks were inoculated with $0 \cdot 1 \mathrm{ml}$. (about equiv. $4 \mu \mathrm{g}$. dry-wt. organism) of aseptically washed Nocardia opaca, originally grown on the appropriate substrate, and then incubated at $\mathbf{2 5}^{\circ}$ in air on a New Brunswick 'Gyrotory' shaker. Growth was followed turbidi- 
metrically and when complete the flask contents and washings were filtered through a tared 'Millipore' filter. The organisms on the filter disc were washed several times to remove dissolved materials derived from the medium; the disc with its organisms was then dried on an aluminium planchet to constant weight in an oven at $105^{\circ}$ and the dry-wt. of the organisms determined. In earlier experiments, $20 \mathrm{ml}$. samples from each flask were centrifuged, the packed organisms washed twice and recentrifuged, made up to the original volume in water and then a $10 \mathrm{ml}$. sample dried to constant weight.

Manometry. Respirometric studies were done by the usual manometric methods (Umbreit, Burris \& Stauffer, 1957) at $30^{\circ}$ with air as gas phase. Duplicate manometer flasks contained (unless otherwise recorded): phosphate buffer ( $\mathrm{pH} \mathrm{7 \cdot 2}$ ), $150 \mu$ moles; substrate, 0.5-10 $\mu$ moles; inhibitors, where required, 0-50 $\mu$ moles; cell suspension, $0.5 \mathrm{ml} . ; 20 \% \mathrm{KOH}$ in the centre well, $0.2 \mathrm{ml}$; t total volume made to $3.0 \mathrm{ml}$. with distilled water. Oxygen uptakes were determined at intervals for 60 min., or longer when required; rates of uptake were calculated over the initial linear part of the curves.

Uptake of radioactive anthranilic acid. Anthranilic acid- (carboxyl- ${ }^{14} \mathrm{C}$ ) was the gift of Dr L. M. Henderson; on assay it was found to have an activity of 102,250 c.p.m./mg. The very small quantity available was mixed with unlabelled carrier anthranilic acid to give a final specific activity of 10,600 c.p.m./ $/ \mu$ mole. The incu-

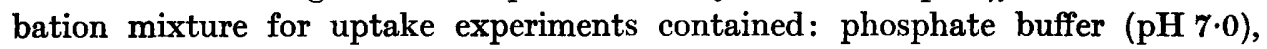
$500 \mu$ moles; anthranilic acid, $200 \mu$ moles; thick cell suspension, $10 \mathrm{ml}$; distilled water to a final volume of $20 \mathrm{ml}$. In one experiment $200 \mu$ moles 0 -nitrobenzoic acid were also added to the incubation mixture. Incubation was at $30^{\circ}$ in a Dubnoff metabolic shaker bath under aerobic conditions. $1 \mathrm{ml}$. samples (equiv. about 3-4 mg. dry-wt. organisms in different experiments) from the incubation mixtures were taken at frequent intervals and the organisms rapidly collected by filtration on a small Millipore filter disc $(1 \mathrm{~cm}$. diam.) where they were washed with $2 \times 2 \mathrm{ml}$. volumes of distilled water. The disc was then transferred to an aluminium planchet where it was fixed with cement to prevent curling and dried under an ultraviolet lamp. The dried planchets were counted under an automatic Picker gas-flow counter (Picker X-ray Co., Oklahoma City) for 200 min. and corrected for the low background count. Results for organisms originally grown with anthranilic, o-nitrobenzoic or succinic acids were corrected to $\mu$ moles uptake/g. dry-wt. organism. The dry weights of organisms in $1 \mathrm{ml}$. samples of each incubation mixture were determined separately by drying samples of twice-washed organisms to constant weight at $105^{\circ}$ on aluminium planchets.

Cell-free preparations. Dried cell preparations were made by spreading the wet paste of organisms thinly over a Petri dish and drying in a vacuum desiccator over $\mathrm{P}_{2} \mathrm{O}_{5}$ or granular anhydrous $\mathrm{CaCl}_{2}$ for 5 days in the cold room at $4^{\circ}$. The dried preparation was ground to a fine powder with a pestle and mortar and stored at $-20^{\circ}$ until required. Cell-free extracts were made by ultrasonic disintegration for $15 \mathrm{~min}$. at 20 kcyc./sec. with the M.S.E.-Mullard instrument or with a Hughes press (Hughes, 1951) without abrasive; in the latter case the frozen crush was thawed, taken up in the minimal quantity of distilled water and centrifuged at $10,000 \mathrm{~g}$ for $30 \mathrm{~min}$. to remove debris and larger particles. The concentration of soluble protein in the extracts was usually about $15 \mathrm{mg} . / \mathrm{ml}$. Cell-free preparations able to convert 
catechol to $\beta$-oxoadipic acid were prepared by extracting freeze-dried organisms with $0.01 \mathrm{M}$-tris-HCl buffer in the cold for $30 \mathrm{~min}$.

Analytical methods. Anthranilic acid was estimated by the Bratton-Marshall procedure (Glazko, Wolf \& Dill, 1949) with twice-recrystallized anthranilic acid as a standard. Nitrite was estimated by the Griess-Ilosvay diazotization method modified by the use of $N, N$-dimethyl- $\alpha$-naphthylamine as coupling reagent (Wallace \& Neave, 1927). Ammonia was determined by nesslerization after distillation into dilute $\mathrm{H}_{2} \mathrm{SO}_{4}$ in Conway micro-diffusion units; and protein by the biuret method of Gornall, Bardawill \& David (1949).

Chemicals. o-Nitrobenzoic acid, anthranilic acid and 3-hydroxyanthranilic acid were recrystallized commercial samples. Anthranilamide, 3,4-dihydroxyanthranilic acid and 5-hydroxyanthranilic acid were the gift of Dr L. M. Henderson. 2-Nitro-3hydroxybenzoic acid (m.p. $174^{\circ}$ ) was synthesized by the method of D'Angeli, Koski \& Henderson (1955). Commercial gentisic acid was recrystallized several times from water and then contained only traces of other dihydroxybenzoic acids as shown by chromatography. cis, cis-Muconic acid, m.p. $197^{\circ}$, was prepared by peracetic acid oxidation of redistilled phenol according to the directions of Elvidge et al. (1950). The corresponding cis,trans-(m.p. $\left.189^{\circ}\right)$ and trans,trans- (m.p. $301^{\circ}$ ) isomers were then prepared from it (Elvidge et al. (1950). (+)-Muconolactone was prepared enzymically from protocatechuic acid by using heat-treated extracts of Moraxella lwoffii мсгв 8250 ('Vibrio 01'; Sebald \& Veron, 1963) which had been grown on $p$-hydroxybenzoate (Cain, 1961). The synthetic $( \pm)$ isomer was the gift of Professor W. C. Evans. $\beta$-Carboxymuconolactone and $\beta$-carboxymuconic acid were prepared enzymically as described previously (Cain, 1961). $\beta$-Oxoadipic enol lactone was prepared from (+)-muconolactone in situ when required (but not isolated) by using extracts of the $\mathrm{ELH}^{-}$mutant of Pseudomonas putida grown upon succinate in the presence of benzoate (Ornston \& Stanier, 1964). This mutant lacks the enzyme enol lactone hydrolase which converts $\beta$-oxoadipic enol lactone to $\beta$-oxoadipic acid. All other chemicals were commercial samples and were used without further purification.

Chromatography. Keto acids were run as their 2,4-dinitrophenylhydrazones in the following solvent systems (all quantities by vol.): (A) tert-amyl alcohol $+n$ propanol +aq. $\mathrm{NH}_{3}$ soln. (sp.gr. 0.880), $(13+1+6)$; (B) $n$-propanol + aq. $\mathrm{NH}_{3}$ soln. (sp.gr. 0 880) + water $(6+3+1)$. Anthranilic acid and phenolic compounds were run in (C) $n$-butanol + acetic acid + water $(4+1+5)$; (D) ethanol +aq. $\mathrm{NH}_{3}$ soln. (sp.gr. 0-880) + water $(40+1+6)$. Arylamine compounds were detected by Ehrlich's reagent [1\%(w/v) $p$-dimethylaminobenzaldehyde in $200 \mathrm{ml}$. $n$-butanol + ethanol $(30: 70, \mathrm{v} / \mathrm{v})+\mathrm{con} . \mathrm{HCl}(30 \mathrm{ml}$.)]. The keto acids were detected by spraying with $\mathrm{N}-\mathrm{NaOH}$ and the phenolic compounds by their fluorescence under u.v. radiation.

Enzymic assays. Conversion of catechol to cis,cis-muconic acid by catechol 1,2oxygenase was followed by increase in extinction at $260 \mathrm{~m} \mu$ with the Unicam SP 800 recording spectrophotometer fitted with the SP 820 constant wavelength attachments; at this wavelength, $\epsilon$ for catechol is 2000 and for cis,cis-muconic acid is 17,200. Cuvettes contained: tris-HCl buffer (pH 7.0) $300 \mu$ moles; catechol, $0.5 \mu$ mole; enzyme equivalent to about $0.1 \mathrm{mg}$. protein; inhibitor or metal ions at concentrations shown in the text; total volume made to $3.0 \mathrm{ml}$. with water. The 
enzyme activity was measured at $30^{\circ}$ in a constant temperature cuvette holder. Under these conditions, the rate of reaction was linear for at least $5 \mathrm{~min}$. and strictly proportional to enzyme concentration.

Lactonizing enzyme in extracts of Nocardia opaca was measured by the decrease in absorption at $260 \mathrm{~m} \mu$ in the presence of $0.5 \mu$ mole $c i s$,cis-muconic acid; muconolactone isomerase by the decrease in the absorption at $225 \mathrm{~m} \mu$ in the presence of $0.5 \mu$ mole $(+)$-muconolactone or, in some cases, $1.0 \mu$ mole of its synthetic $( \pm)$ isomer; $\beta$-oxoadipic enol lactone hydrolase by the decrease in absorption at $225 \mathrm{~m} \mu$ in the presence of $0.5 \mu$ mole $(+)$-muconolactone and excess of crude extract of the benzoate-induced ELH ${ }^{-}$mutant of Pseudomonas putida sufficient to ensure that the muconolactone isomerase of this organism was not rate-limiting (Ornston \& Stanier, 1964; Dr L. N. Ornston, personal communication). Other cuvette contents for these assays were identical with those for catechol-1,2-oxygenase.

\section{RESULTS}

\section{Growth of Nocardia opaca}

Nocardia opaca subcultured from nutrient agar or succinate medium grew equally well in either $o$-nitrobenzoate or anthranilate media (with or without added yeast extract) after a lag of about $20 \mathrm{hr}$. There was, however, a longer lag before growth began in anthranilate medium when the inoculum organisms had been derived from a culture grown with $o$-nitrobenzoate, and the time lag was similarly increased when bacteria growing in o-nitrobenzoate medium were derived from an inoculum grown on anthranilate. Addition of anthranilate to cultures of $N$. opaca growing in $o$-nitrobenzoate media produced very marked differences. When anthranilate was added at the time of inoculation or in the lag phase of growth, the onset of logarithmic growth was delayed by some $15 \mathrm{hr}$ or more. When the anthranilate was added at the beginning of, or during, the log phase, there was no such delay, nor was the growth rate altered as compared with control tubes with no added anthranilate (Fig. 1). A similar effect was found when $o$-nitrobenzoate was added to cultures of $N$. opaca growing on anthranilate; thus, growth which in $10 \mathrm{~mm}$ anthranilate began at $32 \mathrm{hr}$ after inoculation, was delayed for a further 10-12 hr when $5 \mathrm{~mm}$ nitrobenzoate was present in the lag phase, but a similar addition at the beginning of the exponential phase did not affect growth. The extent of the delay in logarithmic growth was also related to the ratio of the concentration of substrate and inhibitor added (Fig. 2), although the lag effect was more pronounced at the same ratio with lower substrate concentrations. o-Nitrobenzoate and anthranilate $(20 \mathrm{~mm})$ both strongly inhibited growth of $N$. opaca on succinate, whereas a nitrobenzoate concentration some fivefold higher was required for comparable inhibition with the flavobacterium strain tested (Kirkland \& Durham, 1963).

\section{Total growth on mixed media}

Although the presence of either anthranilate or 0 -nitrobenzoate increased the time lag in growth on the other substrate, there was no decrease in the final growth yields in the defined medium (Fig. 3). Excellent correlation between available nutrient concentration and final growth yields were found irrespective of whether the two nutrient sources were (i) present together in the medium or (ii) whether 
the second source was added to cultures after growth on the first substrate had ceased. In the former case, there was no evidence of a diauxic response; growth experiments (repeated many times) with anthranilate and $o$-nitrobenzoate present in various proportions always gave an uninterrupted growth curve, the final yield of organism being proportional to the concentration of added substrate. The good correlation between substrate concentration and final growth measured turbidimetrically prompted estimations of the actual yield coefficients ( $\mu \mathrm{g}$. dry-wt. organism formed $/ \mu$ mole substrate utilized; Bauchop \& Elsden, 1960) obtained with

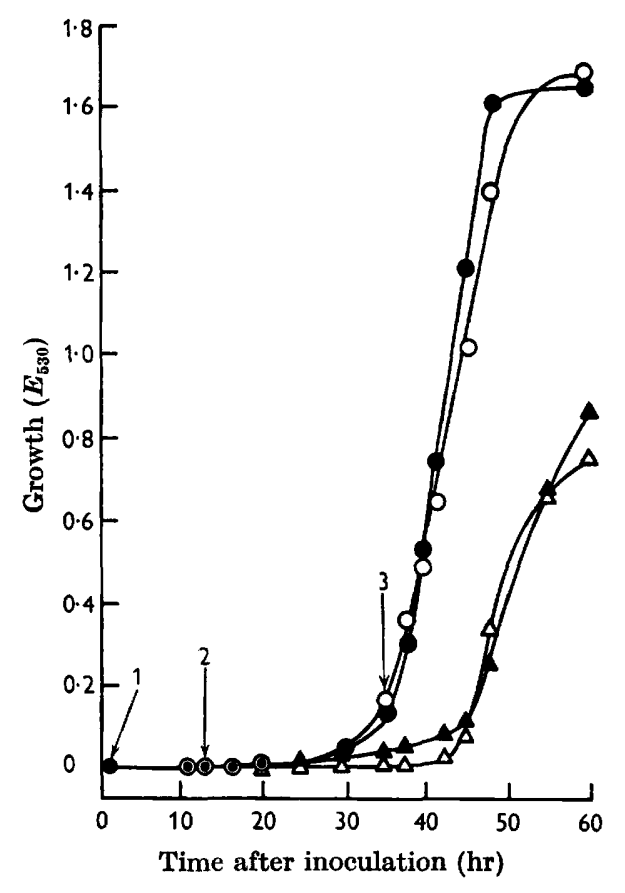

Fig. 1

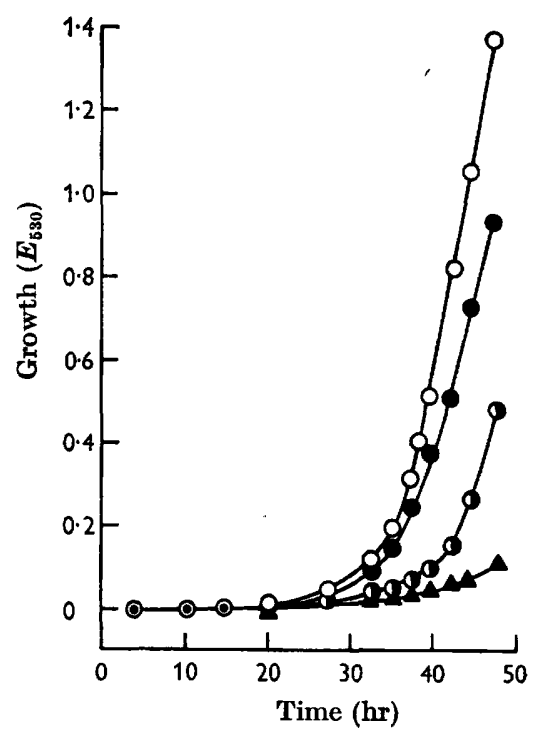

Fig. 2

Fig. 1. The effect of anthranilic acid on the growth of Nocardia opaca with o-nitrobenzoic acid as nutrient source. Anthranilic acid (adjusted to $\mathbf{p H ~ 7 \cdot 0 )}$ was added in different cultures at: 1, inoculation; 2 , in lag phase of growth; or 3, at the beginning of the $\log$ phase of growth as indicated by the three arrows. 0 -Nitrobenzoate $(10 \mathrm{mM})$ only (control); $O$, o-nitrobenzoate $(10 \mathrm{~mm})$ with anthranilic acid $(5 \mathrm{~mm})$ added at the beginning of logarithmic growth; $\Delta, o$-nitrobenzoate $(10 \mathrm{~mm})$ with anthranilic acid $(5 \mathrm{~mm})$ added in the lag phase; $\triangle$, $o$-nitrobenzoate $(10 \mathrm{~mm})$ with anthranilic acid $(5 \mathrm{~mm})$ added at inoculation. Inoculum organisms were grown on 0 -nitrobenzoate.

Fig. 2. The effect of varying the $o$-nitrobenzoate:anthranilate ratio on growth of Nocardia opaca. Two substrate (o-nitrobenzoate) concentrations were used, 10 and $5 \mathrm{~mm}$. 0 , ratio 5:1 (10); $\bullet$, ratio 2.5:1 (5); $O$, ratio 2:1 (10); $\Delta$, ratio $1: 1(10)$. The figures in parentheses give the substrate concentrations (mM) used. The inoculum organisms were originally grown upon 0 -nitrobenzoic acid. Inoculation was made into media containing $o$-nitrobenzoate and anthranilate together at the indicated ratios.

$o$-nitrobenzoate and anthranilate. When these two substrates provided the sole source of carbon, nitrogen and energy, the coefficients were $20 \cdot 2 \pm 0 \cdot 2$ and $23 \cdot 7 \pm 0 \cdot 2$, respectively; in the presence of excess nitrogen provided as $\mathrm{NH}_{4} \overline{\mathrm{Cl}}$, these coefficients 
were raised to $28 \cdot 3 \pm 0 \cdot 7$ and $28 \cdot 3 \pm 0 \cdot 3$, respectively. In some ten experiments the growth yields with anthranilic acid as substrate were always slightly higher than those from the nitro compound.

\section{Inhibition of oxidation by o-nitrobenzoic acid and anthranilic acid}

The inhibition by $o$-nitrobenzoate of the growth of Nocardia opaca utilizing anthranilate suggested that the inhibition might be at the stage of oxidation of the substrate where the nitro compound, because of its similar chemical structure, could compete for the enzyme sites normally occupied by anthranilate. The effects

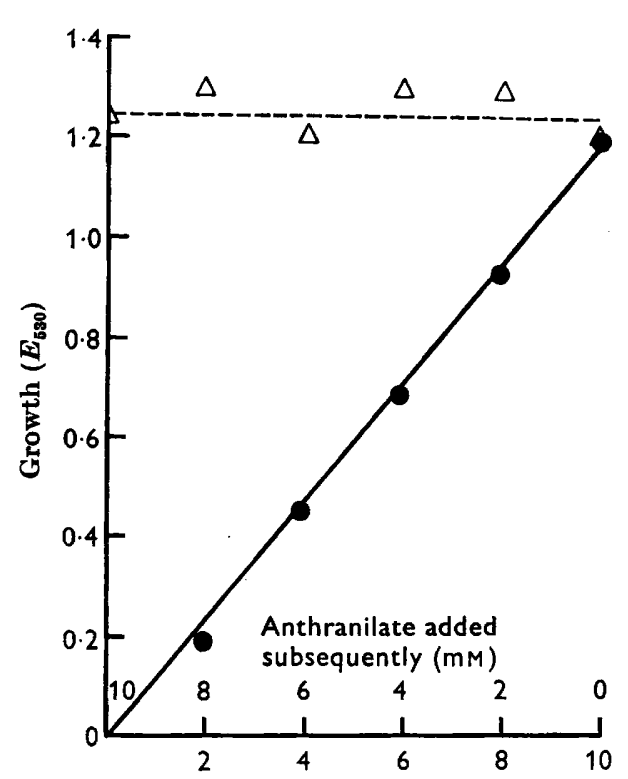

Initial o-nitrobenzoate concentration (mM)

Fig. 3

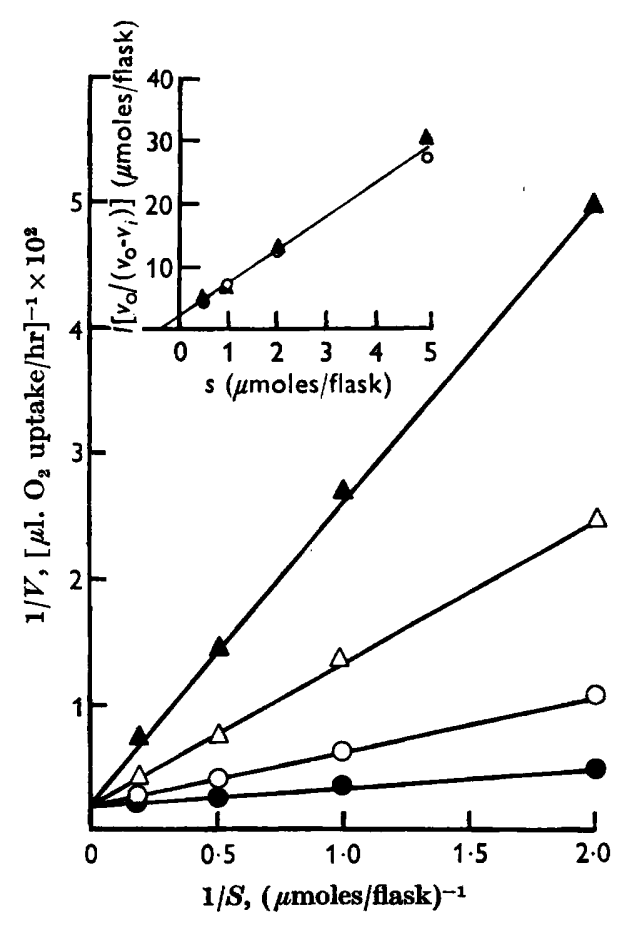

Fig. 4

Fig. 3. The relationship between growth and added substrate concentration. Duplicate cultures of Nocardia opaca were grown with various concentrations of o-nitrobenzoate until growth was complete, $\bullet$. Sodium anthranilate $(\mathrm{pH}$ 7.0) was then added to bring the final aromatic substrate concentration to $10 \mathrm{~mm}$ and incubation was continued until growth had again ceased, $\triangle$.

Fig. 4. Competitive inhibition by o-nitrobenzoic acid of anthranilic acid oxidation in Nocardia opaca. Manometer flask contents as described in Methods with suspension of organisms equivalent to $8.8 \mathrm{mg}$. dry-wt. $O$, No inhibitor; $O, 10 \mu$ moles $o$-nitrobenzoate; $\triangle, 20 \mu$ moles 0 -nitrobenzoate; $\Delta, 50 \mu$ moles $o$-nitrobenzoate. $V$ (the reaction velocity) was calculated as $\mu \mathrm{l} . \mathrm{O}_{2}$ uptake/hr. over the first $30 \mathrm{~min}$., corrected for endogenous respiration. Inset: the results at the $10 \mu$ moles/flask (O) and $50 \mu$ moles/flask (A) inhibitor concentrations plotted by the method of Hunter \& Downs (1945). $v_{0}$ reaction velocity in absence of inhibitor; $v_{i}$, velocity at inhibitor concentration, $I$.

of $o$-nitrobenzoate on anthranilate oxidation were followed manometrically. It was found that a marked inhibition of substrate oxidation occurred; the inhibitory effects were partially annulled by increasing the anthranilate concentration. A 
Lineweaver \& Burk (1934) plot of the results (Fig. 4) showed that the inhibition was competitive. Calculation of the enzyme constants from this plot and by the Hunter \& Downs (1945) method gave mean values of $K_{m}$ for the anthranilate system of $0.12 \mathrm{mM} ; K_{I}$ for 0 -nitrobenzoate inhibition of this system was $1.2 \mathrm{~mm}$, indicating some tenfold preference of the enzyme for its natural substrate. $\mathbf{A}$ similar result was found when anthranilate was added to organisms oxidizing $o$-nitrobenzoate after growth with this substrate; $K_{m}$ for the $\boldsymbol{o}$-nitrobenzoate system was $0.07 \mathrm{mM}$, and $K_{1}$ for the anthranilate inhibition of this system was $2.2 \mathrm{~mm}$. Although these compounds are mutual competitive inhibitors of each other's oxidation, however, the maximum concentrations of anthranilic acid accumulating in 0 -nitrobenzoate medium during growth of $N$. opaca and the flavobacterium (approximately 0.08 and $0.12 \mathrm{~mm}$, respectively) would be insufficient to have any appreciable effect on oxidation of the nitrobenzoate substrate present at some 30fold higher concentration.

\section{Permeability effects}

Anthranilic acid uptake by Nocardia opaca. The rate of uptake of anthranilic acid-(carboxyl-14 $\mathrm{C}$ ) by $N$. opaca was investigated with batches of organisms grown on 0 -nitrobenzoate, anthranilate or succinate as substrates. Organisms originally grown with anthranilate rapidly accumulated labelled anthranilic acid from the incubation mixture, but the accumulated material disappeared equally rapidly because of further metabolism (Fig. 5). (An early step in anthranilate metabolism is conversion to catechol during which the labelled carboxyl group is lost; rapid disappearance of label was, therefore, anticipated.) Anthranilic acid was much more slowly accumulated, however, by organisms grown with 0 -nitrobenzoate or succinate. Simultaneous determinations of the rate of oxidation of anthranilate by these same organisms grown in $o$-nitrobenzoate or in succinate media gave $Q_{\mathrm{O}_{2}}$ values of $\mathbf{3 \cdot 3}$ and 0 , respectively, whereas that of the organisms originally grown with anthranilate was $\mathbf{4 7 \cdot 0}$. It would seem, therefore, that growth on anthranilate was necessary to induce not only the enzyme system capable of oxidizing this substrate but also a transport system for its rapid uptake. A separate experiment in which unlabelled $o$-nitrobenzoate was included in the incubation mixture resulted not only in a significant decrease of the rate of anthranilic acid uptake (19.0 $\mu$ moles/ min./g. dry-wt. organisms decreased to $6 \cdot 2 \mu$ moles/min./g.; $67 \%$ inhibition) but also in increased values of total label accumulated. That is, the subsequent metabolism of anthranilate was being inhibited, a result which confirmed the inhibition by $o$-nitrobenzoate observed in respirometric experiments.

Experiments with organisms with the permeability barrier destroyed. Destruction of the cell membrane of Nocardia opaca organisms by cetyltrimethylammonium bromide (CTAB) at $80 \mu \mathrm{g} . / \mathrm{ml}$. was virtually complete as measured by the release of u.v.-absorbing material. The permeability barrier was also destroyed in dried-cell preparations as indicated by the rapid oxidation of citrate, in contrast to the initial lag period obtained before its oxidation with intact washed organisms (Barrett, Larsen \& Kallio, 1953; Clarke \& Meadow, 1959). Nocardia opaca grown either on o-nitrobenzoate or succinate and then dried or treated with CTAB did not oxidize anthranilate whereas organisms grown with anthranilate and similarly treated, very rapidly oxidized this substrate. 


\section{Effect of an energy source on anthranilate oxidation by unadapted organisms}

Clarke \& Meadow (1959) reasoned that as the induction of new enzyme (protein) synthesis requires energy the addition of small amounts of oxidizable substrates to which organisms were already permeable, should accelerate the induction process and thus decrease the time lag before the inducer was oxidized. In their investigations, induction of a permease was accelerated, but a similar effect would be anticipated for the synthesis of an intracellular enzyme. In the present work Nocardia opaca grown upon o-nitrobenzoate for $24 \mathrm{hr}$ did not oxidize anthranilate for some

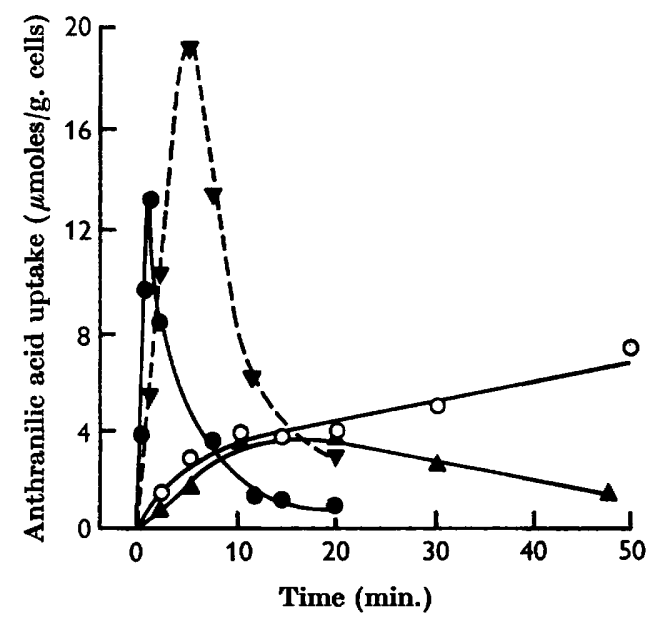

Fig. 5

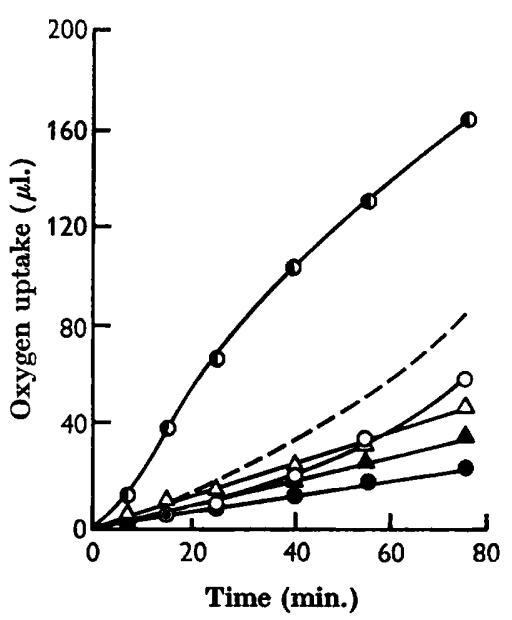

Fig. 6

Fig. 5. Uptake of anthranilic acid-(carboxyl-14C) by Nocardia opaca. Uptake of labelled anthranilic acid was followed in organisms originally grown upon $\bullet$, anthranilic acid; $O$, 0 -nitrobenzoic acid; $\boldsymbol{\Delta}$, succinic acid; (solid lines). Uptake of anthranilic acid was also followed in organisms originally grown on anthranilic acid, but the incubation medium contained an equimolar concentration of (unlabelled) $o$-nitrobenzoic acid, $\nabla$ (dotted line).

Fig. 6. The effect of an energy source (fumarate) upon anthranilic acid oxidation by Nocardia opaca grown on 0 -nitrobenzoic acid. $D$, anthranilic acid +fumaric acid; $O$, anthranilic acid alone; $\Delta$, fumaric acid alone; ---.-., sum of $O$ and $\Delta ; \Delta$, anthranilic acid + fumaric acid + chloramphenicol; $\bullet$, no substrate and no substrate + chloramphenicol. Duplicate flasks contained: anthranilic acid, $5 \mu$ moles; fumaric acid (where required), $0.5 \mu$ mole; chloramphenicol (where required) to $60 \mu \mathrm{g} . / \mathrm{ml}$. Other flask contents as described in Methods.

20-60 min., and then only slowly, but did oxidize fumarate from zero time. In the presence of $0.5 \mu$ mole fumarate, however, anthranilate was rapidly oxidized without a perceptible lag at a rate considerably in excess of the sum of the two components separately (Fig. 6). This adaptation was completely inhibited by chloramphenicol $60 \mu \mathrm{g} . / \mathrm{ml}$, as would be expected of a reaction involving protein synthesis. When a small amount of 0 -nitrobenzoate ( $0.5 \mu \mathrm{mole})$ was substituted for the fumarate as an energy source in this experiment an identical result was obtained. After incubation for $24 \mathrm{hr} o$-nitrobenzoate-grown organisms occasionally show low amounts of the anthranilate oxidation system (Cain, 1966). The usual sigmoid-shaped curve characteristic of new enzyme synthesis was, in such experiments, barely perceptible. 


\section{Intermediary metabolism}

Anthranilic acid production from o-nitrobenzoic acid. Determinations were made of the yields of the major $\boldsymbol{N}$-containing end-products which appeared in the defined medium during growth of Nocardia opaca and the flavobacterium when o-nitrobenzoic acid was the sole source of carbon, nitrogen and energy. The characteristic feature during the growth of both organisms was an accumulation of anthranilate during the log phase of growth, followed by an equally rapid decrease in concentration of anthranilate as the culture entered the stationary phase; with the flavobacterium this decrease was always precipitous, some $80 \%$ or more of the accumulated anthranilate disappearing within 2-3 hr (Fig. 7). The arylamine was identified as anthranilic acid by isolation, chromatography and chemical characterization as

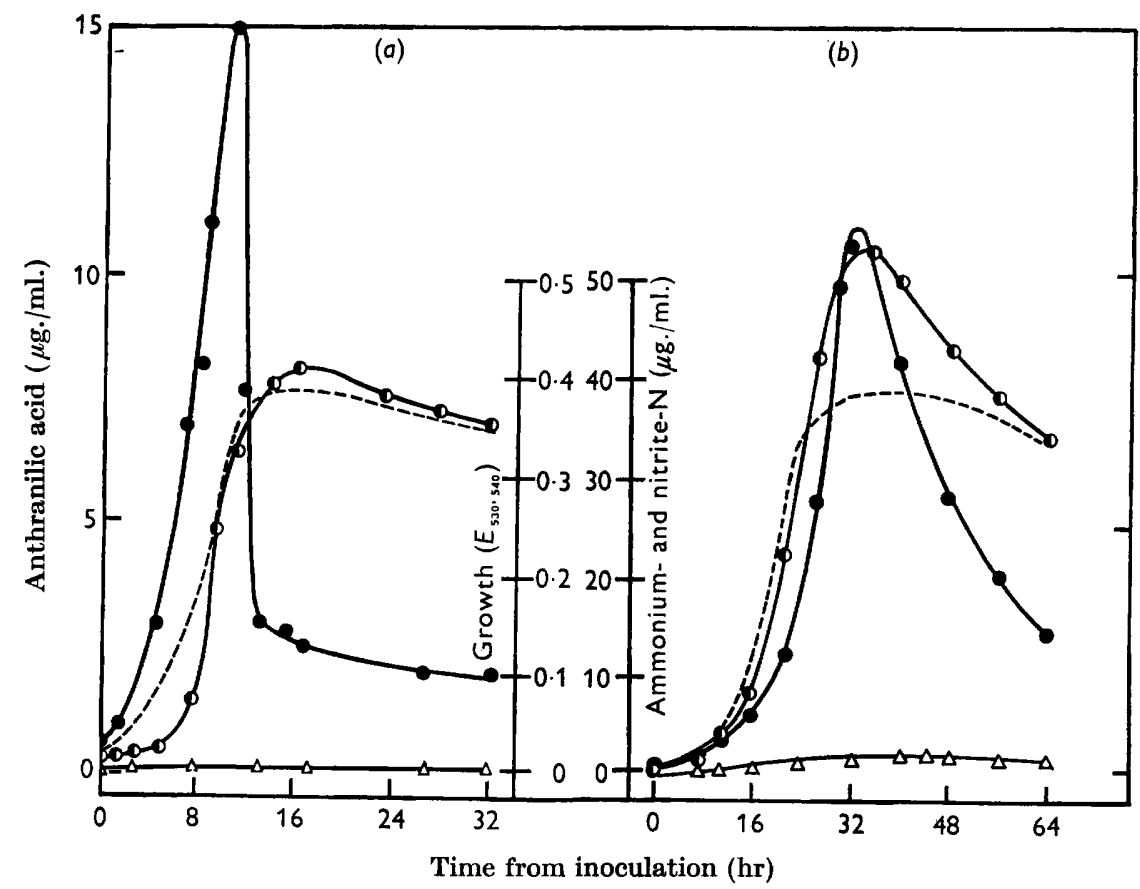

Fig. 7. Metabolic products of $o$-nitrobenzoic acid degradation by (a) flavobacterium; (b) Nocardia opaca. $\bullet$, anthranilic acid; $\Theta$, ammonium-N; $\triangle$, nitrite-N; ...-, growth. Measurements were made on samples from 51 . cultures of each bacterium growing in minimal medium with 0 -nitrobenzoic acid $(0.1 \%, w / v)$ supplying the sole source of carbon, nitrogen and energy.

described by Cartwright \& Cain (1959b). The concentration of anthranilate accumulated by both organisms was 12-14 $\mu \mathrm{g}$. $/ \mathrm{ml}$.; occasionally values as high as $35 \mu \mathrm{g} . / \mathrm{ml}$. were recorded with the flavobacterium. The decrease in anthranilate concentration with both bacteria was always correlated with the appearance of an anthranilate oxidation system (Cain, 1966).

The other important nitrogenous product was ammonia, the production of which in cultures of Nocardia opaca and the flavobacterium closely followed growth. 
Maximum concentrations of ammonia in the medium which supported the growth of the flavobacterium accounted for about $45 \%$ of the total original nitro-N, a considerably larger proportion than the $25 \%$ or so recoverable as this metabolite during degradation of $p$-nitrobenzoic acid by $N$. erythropolis (Cartwright \& Cain, $1959 a$ ). Small amounts of nitrite were also found in cultures of $N$. opaca (up to $0.8 \mu \mathrm{g}$. nitrite- $\mathrm{N} / \mathrm{ml}$.) but the formation of this metabolite by the flavobacterium was negligible (less than $0 \cdot 05 \mu \mathrm{g}$. nitrite- $\mathrm{N} / \mathrm{ml}$.). Only traces of nitrite were formed in cultures of either organism when anthranilate was the organic source, although ammonia yields in these instances paralleled those found in $o$-nitrobenzoate media.

Anthranilate oxidation by washed organisms and extracts. Washed Nocardia opaca harvested from 24 to $30 \mathrm{hr}$ cultures oxidized anthranilate rapidly $\left(Q_{\mathrm{O}_{3}}\right.$ varied from 45 to 72) but consumed only about half the theoretical amount of oxygen and produced only about half the expected $\mathrm{CO}_{2}$ necessary for complete oxidation according to the equation: $\mathrm{C}_{7} \mathrm{H}_{7} \mathrm{NO}_{2}+7 \mathrm{O}_{2} \rightarrow 7 \mathrm{CO}_{2}+2 \mathrm{H}_{2} \mathrm{O}+\mathrm{NH}_{3}$. Sodium azide prevented the considerable oxidative metabolism (Clifton, 1946) observed with washed suspensions; in the presence of $7 \mathrm{~mm}$ azide the theoretical figures for oxidation according to the above equation were obtained (Table 1). The nitrogen of the anthranilate substrate appeared solely as ammonia; the quantity, unaffected by azide, varied between 70 and $100 \%$ of that required by theory.

Table 1. Oxidation of anthranilic acid by washed Nocardia opaca

\begin{tabular}{clll} 
& \multicolumn{3}{c}{$\begin{array}{c}\text { Moles consumed or produced/mole } \\
\text { substrate oxidized }\end{array}$} \\
\cline { 2 - 4 } & $\mathrm{O}_{2}$ & $\mathrm{CO}_{2}$ & $\mathrm{NH}_{3}$ \\
None & $3 \cdot 7(10) *$ & $3 \cdot 9(6)$ & $0 \cdot 82(10)$ \\
$\mathbf{3}$ & $\mathbf{5 \cdot 6 ( 1 )}$ & $6 \cdot 5(1)$ & $0 \cdot 72(1)$ \\
$\mathbf{5}$ & $\mathbf{6 \cdot 4}(1)$ & $6 \cdot 7(1)$ & $0 \cdot 77(1)$ \\
7 & $6 \cdot 9(2)$ & $7 \cdot 0(2)$ & $0 \cdot 80(2)$ \\
Theoretical value & $\mathbf{7 \cdot 0}$ & $7 \cdot 0$ & $1 \cdot 0$ \\
(equation, see above) & & &
\end{tabular}

* Figures in parentheses represent the number of experiments carried out under those conditions, and the results are the means of data obtained from all such experiments.

Extracts, prepared in $0.01 \mathrm{~m}$-phosphate buffer ( $\mathrm{pH} 7 \cdot 0$ ) by ultrasonic disintegration or by the Hughes press, did not oxidize anthranilic acid even after supplementation with substrate quantities of NADH, NADPH or catalytic amounts of NAD or NADP and the requisite reducing systems (alcohol dehydrogenase + ethanol and isocitric dehydrogenase + isocitrate, respectively). The anthranilic oxidizing system in Nocardia opaca thus appears much more labile than that of the pseudomonas examined by Higashi \& Sakamoto (1960), Hosokawa, Nakagawa \& Takeda (1961) and Taniuchi et al. (1964) in which a NADH-mediated anthranilic hydroxylase system was detected.

Oxidation of probable intermediates by roashed suspensions. Washed suspensions of Nocardia opaca harvested at $\mathbf{2 4} \mathrm{hr}$ from yeast extract-enriched $\theta$-nitrobenzoate and anthranilate cultures were tested for ability to oxidize a wide variety of related compounds and probable intermediates. Catechol was the only compound oxidized at a rate comparable with that of $o$-nitrobenzoate or anthranilate by such organisms. 
Salicyclic and gentisic acids, the most likely intermediates (Ke et al., 1959; Ladd, 1962), were oxidized at low rates or not at all. 2-Nitro-3-hydroxybenzoic acid, anthranilamide, 3,4-dihydroxyanthranilic acid (after correction for non-enzymic oxidation), kynurenine, kynurenic and 2,3-dihydroxybenzoic acids also did not stimulate oxygen uptake above the endogenous value.

3-Hydroxyanthranilate was also oxidized without lag by Nocardia opaca grown on o-nitrobenzoate or anthranilate. Oxidation ceased at 1.5 and 2 moles $\mathrm{O}_{2}$ consumed/mole substrate oxidized, respectively; these were well below the figures required for complete oxidation even allowing for 10-30\% assimilation as found with $o$-nitrobenzoate itself. The corresponding 5 -isomer was also oxidized but this oxidation, though not that of anthranilate or catechol, was almost entirely abolished by previous incubation with chloramphenicol (30 $\mu \mathrm{g} . / \mathrm{ml}$. final concentration). The evidence suggests, therefore, that catechol is an intermediate common to the pathways for 0 -nitrobenzoic and anthranilic acids. Catechol oxidation was also observed with dried preparations of organisms harvested in the log phase from anthranilate but not from succinate media.

Catechol-1,2-oxygenase activity in extracts of Nocardia opaca. Cain \& Cartwright $(1960 a)$ found that growth of Nocardia opaca on o-nitrobenzoic acid induced catechol-1,2-oxygenase activity, and they described some of the properties of the enzyme in this organism. Growth of this organism upon anthranilic acid also induced catechol-1,2-oxygenase; the enzyme was completely absent, however, from extracts of organisms grown in nutrient broth or fumarate medium (as measured manometrically or by the more sensitive spectrophotometric method).

Extracts of anthranilate-grown Nocardia opaca prepared by the Hughes press or by ultrasonic disintegration resembled those derived from 0 -nitrobenzoate cultures in being unable to metabolize catechol to $\beta$-oxoadipate, although dried organism preparations effected this change. The extracts converted catechol quantitatively to cis,cis-muconic acid which was not further metabolized, although the enzymes for converting $(+)$-muconolactone or its synthetic $( \pm)$ isomer and $\beta$-oxoadipic enol lactone to $\beta$-oxoadipate were present. The amounts of the enzymes present in extracts of dried organisms grown on anthranilate and fumarate, respectively (Table 2), showed clearly that the complete enzyme sequence for converting catechol to $\beta$-oxoadipate was induced by growth on anthranilate. The same extracts also had activity towards some related metabolites such as protocatechuate $(0 \cdot 36 \mu$ mole degraded/hr/mg. enzyme protein) and $\beta$-carboxymuconate $(10 \cdot 0 \mu \mathrm{moles} / \mathrm{hr} / \mathrm{mg}$. protein); but $\beta$-carboxymuconolactone was not attacked. The inability of crude extracts to lactonize cis,cis-muconate enabled some properties of the catechol-1,2oxygenase to be studied conveniently. Extracts which converted catechol to cis,cis-muconate were fractionated with ammonium sulphate, all the activity being precipitated in the $\mathbf{3 3 - 4 5 \%}$ saturation range. This fraction, after dialysis against water for $12 \mathrm{hr}$, was used as enzyme source; it was very active only for catechol. 3,4-Dihydroxybenzoate (protocatechuate) was slowly attacked by the same preparation but the corresponding 2,3-, 2,5- and 3,5-isomers were not utilized nor did they act as inhibitors of catechol oxidation.

The product of catechol oxidation by extracts was identified as follows. Catechol was added in $1 \mathrm{~m}$-mole quantities to $150 \mathrm{ml}$. $0 \cdot 1 \mathrm{M}$-phosphate buffer $(\mathrm{pH} \mathrm{7 \cdot 0})$ at $25^{\circ}$ containing cell-extract equivalent to $40 \mathrm{mg}$. protein and $0.1 \mathrm{mM}-\mathrm{Fe}^{2+}$. Aeration was 
done by a magnetic stirrer sufficiently rapid to form a vortex in the liquid to the base of the $500 \mathrm{ml}$. reaction vessel. The reaction was followed manometrically in a pilot vessel, further catechol, to a total of $5 \mathrm{~m}$-moles, being added to the main reaction flask when the oxygen uptake in the pilot vessel had ceased. The solution was maintained at $\mathrm{pH} 7 \cdot 0$ by adding $0 \cdot 1 \mathrm{~N}-\mathrm{NaOH}$. At the completion of the reaction the contents were deproteinized with $10 \%$ metaphosphoric acid and the acidified solution ether extracted five times with 0.25 vol. of ether. After drying over anhydrous $\mathrm{Na}_{2} \mathrm{SO}_{4}$, the combined ether fractions were evaporated to dryness and

Table 2. The amounts of enzymes catalyzing the conversion of catechol to $\beta$-oxoadipic acid in extracts of Nocardia opaca

\begin{tabular}{|c|c|c|c|}
\hline \multirow[b]{2}{*}{ Enzyme } & \multirow[b]{2}{*}{ Reaction catalysed } & \multicolumn{2}{|c|}{$\begin{array}{c}\text { Rate of substrate } \\
\text { decomposition } \\
\text { ( } \mu \text { moles/hr/mg. protein })\end{array}$} \\
\hline & & $\begin{array}{l}\text { Anthranilate- } \\
\text { grown }\end{array}$ & $\begin{array}{l}\text { Fumarate- } \\
\text { grown }\end{array}$ \\
\hline Catechol-1,2-oxygenase & catechol to cis,cis-muconate & $7 \cdot 9$ & $\mathbf{0}$ \\
\hline Lactonizing enzyme & $\begin{array}{l}\text { cis, cis-muconate to }(+)- \\
\text { muconolactone }\end{array}$ & $0 \cdot 6$ & $\mathbf{0}$ \\
\hline Muconolactone isomerase & $\begin{array}{l}(+) \text { - or }( \pm) \text {-muconolactone to } \\
\beta \text {-oxoadipic enol lactone }\end{array}$ & $\begin{array}{ll}(a)^{*} & 4 \cdot 4 \\
(b) & 4 \cdot 3\end{array}$ & $\begin{array}{l}0.07 \\
-\end{array}$ \\
\hline$\beta$-Ketoadipic enol lactone hydrolase & $\begin{array}{l}\beta \text {-oxoadipic enol lactone to } \\
\beta \text {-oxoadipate }\end{array}$ & 6.0 & $0 \cdot 1$ \\
\hline
\end{tabular}

the residue recrystallized from hot absolute ethanol. cis,cis-Muconic acid (300 mg.) crystallized as off-white needles, m.p. $195^{\circ}$. The mixed m.p. with authentic material (m.p. $197^{\circ}$ ) was $196^{\circ}$; with the authentic cis,trans-isomer (m.p. $189^{\circ}$ ) the mixed m.p. was $167^{\circ}$. The enzymically-prepared material had two titratable carboxylic acid groups and an equivalent of 70 from titration data; cis,cis-muconic acid requires 71. The prepared material was identical with synthetic cis,cis-muconic acid when chromatographed in solvents (C) and (D). After reduction of this material in water with hydrogen and Adam's catalyst (platinic oxide) the reduction product was extracted into ether, the ether evaporated off and the residue recrystallized from ethyl acetate+ benzene. This product did not depress the m.p. of adipic acid $\left(152^{\circ}\right)$.

The effects of some inhibitors on the enzyme are shown in Table 3; from this it is clear that only metal-chelating agents and sulphydryl reagents brought about significant inhibition. The inhibition by EDTA, 2,2'-dipyridyl and 1,10-phenanthroline was almost completely annulled by $\mathrm{Fe}^{2+}$, and that due to mercury compounds by L-cysteine or reduced glutathione. The inhibitory effect of $0.01 \mathrm{mM}^{-\mathrm{HgCl}_{2}}$ was not so severe when added after enzyme and substrate had already reacted (53\% inhibition) as when pre-incubated with enzyme for $10 \mathrm{~min}$. at $30^{\circ}$ (90\% inhibition). Both these inhibitions were annulled by $1 \mathrm{~mm}-\mathrm{L}$-cysteine, but not by $0 \cdot 1 \mathrm{~mm}-\mathrm{Fe}^{2+}$ to any degree. This suggests that sulphydryl groups are probably involved at the active site of the enzyme, a conclusion which Suda \& Tokuyama (1958) reached about a purified pyrocatechase (catechol-1,2-oxygenase) from a pseudomonad.

Added divalent metal ions $(0 \cdot 1 \mathrm{~mm})$ were uniformly without effect except for 
$\mathrm{Fe}^{2+}$ which produced a more than twofold stimulation of enzyme activity of the ammonium sulphate fractionated enzyme preparations, and $\mathrm{Cu}^{2+}$ which caused some $42 \%$ inhibition. The copper inhibition was progressive and not relieved by subsequent addition of equimolar $\mathrm{Fe}^{2+}$ or by reduced glutathione (compare Hayaishi, Katagiri \& Rothberg, 1957). Crude extracts showed no decrease in activity after dialysis for $24 \mathrm{hr}$ against $1 \mathrm{~mm} 2,2^{\prime}$-dipyridyl or EDTA.

Table 3. The effect of inhibitors on catechol-1,2-oxygenase

of Nocardia opaca

\begin{tabular}{|c|c|c|c|c|c|c|}
\hline \multirow[b]{2}{*}{ Substance added } & \multirow{2}{*}{$\begin{array}{l}\text { Concen- } \\
\text { tration } \\
(\mathrm{mM})\end{array}$} & \multicolumn{3}{|c|}{$\Delta E_{2} *$} & \multirow{2}{*}{$\begin{array}{l}\mu l . \mathrm{O}_{2} \\
\text { uptake† } \\
/ \mathrm{hr}\end{array}$} & \multirow{2}{*}{$\begin{array}{l}\text { Percent } \\
\text { inhibi- } \\
\text { tion } \ddagger\end{array}$} \\
\hline & & (1) & (2) & (3) & & \\
\hline None & - & $0 \cdot 198$ & $0 \cdot 170$ & $0 \cdot 166$ & - & - \\
\hline EDTA & 1 & $0 \cdot 154$ & - & - & - & 22 \\
\hline EDTA & 3 & - & - & $0 \cdot 098$ & - & 41 \\
\hline Sodium azide & 1 & $0 \cdot 196$ & - & - & - & 1 \\
\hline Sodium fluoride & 1 & $0 \cdot 172$ & - & - & - & 13 \\
\hline Sodium arsenite & 1 & $0 \cdot 150$ & - & - & - & 24 \\
\hline Sodium arsenate & 1 & $0 \cdot 158$ & - & - & - & 20 \\
\hline Mercuric chloride & 0.01 & - & 0.016 & - & - & 90 \\
\hline $\begin{array}{l}\text { Mercuric chloride + reduced } \\
\text { glutathione }\end{array}$ & $\left.\begin{array}{l}0 \cdot 01 \\
1\end{array}\right\}$ & - & 0.220 & - & - & $(+) \mathbf{2 9}$ \\
\hline$p$-Chloromercuribenzoic & $0 \cdot 1$ & 0.043 & - & - & - & 77 \\
\hline acid & $0 \cdot 01$ & $0 \cdot 144$ & - & - & - & 27 \\
\hline $\begin{array}{l}p \text {-Chloromercuribenzoic } \\
\text { acid } \\
\text { + reduced glutathione }\end{array}$ & $0 \cdot 1)$ & 0.134 & - & - & - & 21 \\
\hline $\begin{array}{l}p \text {-Chloromercuribenzoic } \\
\text { acid } \\
\text { +reduced glutathione }\end{array}$ & $\left.\begin{array}{c}0 \cdot 01 \\
1\end{array}\right\}$ & - & $0 \cdot 170$ & - & - & $\mathbf{0}$ \\
\hline Reduced glutathione & 10 & $0 \cdot 142$ & - & - & - & 28 \\
\hline L-Cysteine & 1 & - & - & $0 \cdot 320$ & - & $(+) 93 \cdot 0$ \\
\hline None & - & - & - & - & 189 & - \\
\hline 2,2'-Dipyridyl & 1 & - & - & - & 87 & $\mathbf{5 4}$ \\
\hline 1,10-Phenanthroline & 1 & - & - & - & 96 & 49 \\
\hline 8-Hydroxyquinoline & 1 & - & - & - & 72 & 62 \\
\hline $\begin{array}{l}\text { 2,2'-Dipyridyl } \\
+\mathrm{Fe}^{2+}\end{array}$ & 1) & 一 & - & 一 & 180 & 5 \\
\hline
\end{tabular}

* Under (1), (2) and (3) in this column are results for separate experiments.

$\uparrow$ Manometric determinations were necessary with these chelating agents because of their high extinction at $260 \mathrm{~m} \mu$. Flasks contained $5 \mu$ moles catechol and the enzyme protein (1.2 mg.) was incubated with the inhibitors for $10 \mathrm{~min}$. before tipping substrate. Uptake figures are corrected for endogenous respiration.

$\ddagger(+)$ sign in this column means stimulation.

The Michaelis constant determined for the ammonium sulphate fractionated extract from organisms grown on anthranilate gave a $K_{m}=8 \mu \mathrm{M}$ from a double reciprocal plot. This compares favourably with the $K_{m}=11 \mu \mathrm{M}$ found for the same enzyme in this Nocardia opaca when induced by growth on o-nitrobenzoate, but is higher than that of a pseudomonas pyrocatechase $(0.5 \mu \mathrm{M})$ induced by growth on tryptophan (Hayaishi et al. 1957). 


\section{DISCUSSION}

Utilization of nitro- and amino-phenyl compounds as sources of microbial carbon and nitrogen are well known, actinomycetes and pseudomonads being particularly efficient in this respect (Simpson \& Evans, 1953; Durham, 1956; Gundersen \& Jensen, 1956; Cain, 1958; Cartwright \& Cain, 1959 $a$; Ladd, 1962; Taniuchi et al. 1964). Although in some cases reduction of the nitro group precedes assimilation (Durham, 1958) in others the nitro group is released as nitrite ion (Gundersen \& Jensen, 1956; Cain \& Cartwright, 1960 b). Corresponding nitro- and amino-phenyl derivatives may be degraded in the early stages by quite independent metabolic routes, though in most cases these pathways converge at common hydroxylated intermediates. It might be expected, therefore, that the molar growth yields from carbocyclic aromatic compounds and their nitro- and amino-derivatives would be comparable so long as the nitrogen content of the derivatives was not limiting growth. In mononitro- and monoamino-substituted aromatic compounds, the nitrogen content is probably always limiting since it comprises less than $10 \%$ of the total molecular weight. The increased yield coefficients of Nocardia opaca upon addition of a source of ammonium-N (the form in which nitrobenzoate- and aminobenzoate- $\mathbf{N}$ ultimately appears in cultures of this organism) reported here, substantiate this suggestion. Even with supplementary nitrogen, however, the molar growth yields of $N$. opaca upon anthranilate were always equal to, or slightly greater than, those given upon o-nitrobenzoate; this suggests that the organism can obtain no energy from a reduction of the nitro group in this substrate, which it is known to effect (Cartwright \& Cain, 1959b).

Cain (1966) produced evidence that anthranilic acid is not a direct intermediate in the metabolism of $o$-nitrobenzoate by Nocardia opaca, although it appears transiently in the culture medium. These conclusions are reinforced by several observations reported here: (i) the mutual inhibitory effects of o-nitrobenzoic and anthranilic acids in growth and in oxidation, confirmed in the latter case by the isotopic experiments; (ii) the lag of some $28 \mathrm{hr}$ before an inoculum of $o$-nitrobenzoate-grown organisms began to produce measurable growth in anthranilate media; (iii) the long adaptation time for $o$-nitrobenzoate-grown washed organisms to begin to oxidize anthranilic acid and the low degree of activity even after induction; (iv) $N$. opaca grown upon $o$-nitrobenzoate accumulated anthranilate only very slowly.

Numerous differences in the properties of the catechol-1,2-oxygenases induced in Nocardia opaca by growth on anthranilate and $o$-nitrobenzoate were also observed although it should be emphasized that only partially purified enzyme preparations were used. In particular, the nitrobenzoate-induced enzyme was active only when prepared and reacted in the presence of L-cysteine (Cain \& Cartwright, 1960a), whereas the anthranilate-induced enzyme was quite stable in the absence of sulphydryl compounds; the former was rapidly inactivated by dialysis against water or $2,2^{\prime}$-dipyridyl, whereas the latter was unaffected by dialysis for $48 \mathrm{hr}$ against these materials. The effects of chelating agents on the two enzymes were also different. There is little doubt from the accumulated evidence that the energy-yielding pathway of $o$-nitrobenzoate metabolism does not involve anthranilic acid and that the pathways for these two substrates are distinct. 
The assistance of Miss J. Darrah, M.Sc., in the concluding experiments of this study is gratefully acknowledged. I wish to thank Dr N. N. Durham and Dr E. A. Grula for useful discussions. The work was financed in the U.S.A. by a grant (GB 166) from the National Science Foundation and by the Oklahoma Agricultural Experiment Station, Project No. 1027, 1962-63.

\section{REFERENCES}

Barnett, J. A. \& Ingram, M. (1955). Technique in the study of yeast assimilation reactions. J. appl. Bact. 18, 131.

BarretT, J. T., LARSEn, A. D. \& Kalijo, R. E. (1953). The nature of the adaptive lag of Pseudomonas fluorescens towards citrate. J. Bact. 65, 187.

BAUCHOP, T. \& ElSDEN, S. R. (1960). The growth of micro-organisms in relation to their energy supply. J. gen. Microbiol. 23, 457.

Behrman, E. J. (1962). Tryptophan metabolism in Pseudomonas. Nature, Lond. 196, 150.

CaIN, R. B. (1958). The microbial metabolism of nitro-aromatic compounds. J. gen. Microbiol. 19, 1.

CAIN, R. B. (1961). The metabolism of protocatechuic acid by a Vibrio. Biochem. J. 79, 298.

CAIN, R. B. (1966). Induction of an anthranilate oxidation system during the metabolism of ortho-nitrobenzoate by certain bacteria. J. gen. Microbiol. 42, 197.

CaIn, R. B. \& Cartwright, N. J. (1960a). On the properties of some aromatic ringopening enzymes of species of the genus Nocardia. Biochim. Biophys. Acta, 37, 197.

CaIN, R. B. \& CARTwright, N. J. (1960b). Intermediary metabolism of the nitrobenzoic acids by bacteria. Nature, Lond. 185,868 .

Cartwright, N. J. \& Cain, R.B. (1959a). Bacterial degradation of the nitrobenzoic acids. Biochem. J. 71, 248.

CARTwright, N. J. \& CAIN, R. B. (1959b). Bacterial degradation of the nitrobenzoic acids. 2. Reduction of the nitro group. Biochem. J. 73, 305 .

ClaAkE, P. H. \& Meadow, P. M. (1959). Evidence for the occurrence of permeases for tricarboxylic acid cycle intermediates in Pseudomonas aeruginosa. J. gen. Microbiol. 20, 144.

Clifton, C. E. (1946). Microbial assimilations. Advanc. Enzymol. 6, 269.

D'Angeli, F., Koski, R. E. \& Henderson, L. M. (1955). Metabolism of compounds related to 3-hydroxyanthranilic acid. J. biol. Chem. 214, 781 .

Doy, C. H. \& GIBson, F. (1961). The formation of 4-hydroxyphenyl-pyruvic acid and phenylpyruvic acid by tryptophan auxotrophs and wild-type Aerobacter aerogenes considered in relation to the general aromatic pathway. Biochim. Biophys. Acta, 50, 495.

Durham, N. N. (1956). Bacterial oxidation of $p$-aminobenzoic acid by Pseudomonas fluorescens. J. Bact. 72, 333.

Durham, N. N. (1958). Studies on the metabolism of $p$-nitrobenzoic acid. Can.J. Microbiol. 4,141 .

Durham, N. N. \& Hubbard, J. S. (1959). Antagonism of the oxidative assimilation of $p$-aminobenzoic acid by $p$-aminosalicylic acid. Nature, Lond. 184, 1398.

Elvidge, J. A., Linstead, R. P., Orkin, B. A., Sims, P., Baer, H. \& Pattison, D. B. (1950). Unsaturated lactones and related substances. Part IV. Lactonic products derived from muconic acid. J. chem. Soc. p. 2228.

Glazko, A. J., Wolf, L. M. \& Dill, W. A. (1949). Biochemical studies on chloramphenicol. I. Colorimetric methods for the determination of chloramphenicol and related nitrocompounds. Arch. Biochem. 23, 411.

Gornall, A. G., Bardawill, C. J. \& David, M. M. (1949). Determination of serum proteins by means of the biuret reaction. J. biol. Chem. 177, 751.

Gundersen, K. \& Jensen, H. L. (1956). A soil bacterium decomposing organic nitrocompounds. Acta agric. scand. 6, 100. 
Hayaishi, O., Katagiri, M. \& Rothberg, S. (1957). Studies on oxygenases. Pyrocatechase. J. biol. Chem. $229,905$.

Hrgashi, T. \& Sakamoto, Y. (1960). Oxidation of anthranilic acid catalysed by Pseudomonas cell-free extract. $J$. Biochem. (Tokyo), 48, 147.

Hosokawa, K., Nakagawa, H. \& Takeda, A. (1961). Cofactor requirements for anthranilate oxidase. J. Biochem. (Tokyo), 49, 355.

Hughes, D. E. (1951). A press for disrupting bacteria and other micro-organisms. Br. $J$. exp. Path. 32, 97.

HunTER, A. \& Downs, C. E. (1945). The inhibition of arginase by amino acids. J. biol. Chem. 157, 427.

KE, Y-H., GEe, L. L. \& DurhaM, N. N. (1959). Mechanism involved in the metabolism of nitrophenyl-carboxylic acid compounds by micro-organisms. J. Bact. 77, 593.

KIRKLAND, J. J. \& DURHAM, N. N. (1963). Reversal of $o$-nitrobenzoic acid inhibition of microbial growth by amino acids. Nature, Lond. 197, 210.

KNox, W. E. (1959). The enzymes of tryptophan metabolism. In Symposium on Tryptophan Metabolism. Amer. Chem. Soc., Div. Med. Chem., 137th Meeting, Atlantic City, N.J.

LADD, J. N. (1962). Oxidation of anthranilic acid by a species of Achromobacter isolated from soil. Nature, Lond. 194, 1099.

Lineweaver, H. \& Burk, D. J. (1934). The determination of enzyme dissociation constants. J. Amer, chem. Soc., 56, 658.

Lingens, F., Hildinger, M. \& Hellman, H. (1958). 1-(o-Carboxyphenyl-amino)-1desoxyfructose in der Tryptophan-Biosynthese. Biochim. Biophys. Acta, 30, 668.

Martin, J. R. \& Durham, N. N. (1962). Microbial oxidation of D-tryptophan. Arch. Biochem. Biophys. 96, 190.

Ornston, L. N. \& Stanier, R. Y. (1964). Mechanism of $\beta$-ketoadipate formation by bacteria. Nature, Lond. 204, 1279.

Sebaid, M. \& Veron, M. (1963). Teneur en bases de l'ADN et classification des vibrions. Ann. Inst. Pasteur, 105, 879.

Simpson, J. L. \& Evans, W. C. (1953). The metabolism of nitrophenols by certain bacteria. Biochem. J. 52, 24, P.

Suda, M. \& Tokuyama, T. (1958). Quoted by Mehler, A. H. (1961). In Oxygenases. Ed. by 0 . Hayaishi. London: Academic Press.

Suda, M., Hayaishi, O. \& Oda, Y. (1950). Studies on enzymatic adaptation. Med. J. Osaka Univ. 2, 21.

Taniuchi, H., Hatanaka, M., Kuno, S., Hayaishi, O., Nakajima, M. \& Kurihara, N. (1964). Enzymatic formation of catechol from anthranilic acid. J. biol. Chem. 239, 2204.

Umbreit, W. W., Burris, R. H. \& Stauffer, J. F. (1957). Manometric Techniques. Minneapolis: Burgess Publ. Co.

Wallace, G. I. \& Neave, S. L. (1927). The nitrite test as applied to bacterial cultures. J. Bact. 14, 377.

Wiss, O. \& HeLlman, H. (1953). Über die Einführung phenolischer Hydroxylgruppen beim oxidativen Tryptophan-Stoffwechsel. Z. Naturforsch. 8b, 70.

YANOFSKY, C. (1956). Enzymatic studies with a series of tryptophan auxotrophs of Escherichia coli. J. biol. Chem. 224, 783.

YANOFSKy, C. \& RAChmeler, M. (1958). The exclusion of free indole as an intermediate in the biosynthesis of tryptophan in Neurospora crassa. Biochim. Biophys. Acta, 28, 640. 